Lin David (Orcid ID: 0000-0003-2712-732X)

Title page:

How do I perform Whole Blood Exchange?

David Ming-Hung Lin ${ }^{1}$, Joanne Becker ${ }^{2}$, YanYun $\mathrm{Wu}^{1}$, Laura Cooling ${ }^{3}$

1. Bloodworks, Seattle, WA

2. Roswell Park Comprehensive Cancer Center, Buffalo, NY

3. University of Michigan, Ann Arbor, MI

Corresponding Author:

David Ming-Hung Lin

dlin@bloodworksnw.org

921 Terry Ave, Seattle, WA 98198

Dr. Lin, Dr. Becker, and Dr. Cooling contributed equally to this manuscript.

There are no reported conflict of interest

Key words: Whole blood exchange, Therapeutic Apheresis, Transfusion

This is the author manuscript accepted for publication and has undergone full peer review but has not been through the copyediting, typesetting, pagination and proofreading process, which may lead to differences between this version and the Version of Record. Please cite this article as doi: $10.1111 / \operatorname{trf} .15660$

This article is protected by copyright. All rights reserved. 


\section{How do I perform Whole Blood Exchange?}

\section{Introduction}

There are a number of clinical scenarios where simultaneous exchange of the patient's plasma and red blood cells (RBC) are indicated. Some of the clinical indications for therapeutic whole blood exchange (WBEx) include hemolytic disease of the newborn (HDFN), severe autoimmune hemolytic anemia (AIHA), babesiosis, sickle cell disease, and hyperleukocytosis ${ }^{1,2,3,4}$. WBEx has been performed with manual, semi-automated, and fully automated methods using replacements fluids (i.e. RBC with plasma, RBC with $5 \%$ albumin, and whole blood (WB)) reconstituted to a pre-specified target hematocrit (Hct); however, methodologies vary widely and each carry advantages and disadvantages. Here, we describe our combined experiences in performing WBEx, including clinical indications, technical methods, and issues related to their application in the treatment of patients.

\section{Manual WBEx}

\section{A. Immune Hemolytic Anemia}

Manual WBEx has been used in pediatric and adult patients with severe AlHA with brisk hemolysis that is unresponsive to standard treatment and simple transfusion 
5, 6, 7, 8 . Manual WBEx for severe AIHA has several potential advantages over therapeutic plasma exchange (TPE) alone. First and foremost, WBEx can remove both free and RBCbound antibodies. Furthermore, the infusion and subsequent removal of donor RBC over the course of several hours permits an "in vivo allo-adsorption" of autoantibodies, with reduction in autoantibody titers. In many cases, a single WBEx effected a dramatic decrease in hemolysis 5, 6,7. WBEx may slow hemolysis through removal of antibodies, sensitized RBCs, and hemoglobin byproducts (free iron, methemoglobin) - the latter are hypothesized to synergize and amplify hemolysis in malaria and other chronic nonimmune mediated hemolytic conditions such as sickle cell anemia ${ }^{9,10}$.

At the University of Michigan, manual WBEx method for severe AlHA is performed similar to that for HDFN. Reconstituted WB is prepared with type-specific RBC and plasma to a target Hct of $50 \%$ for a $1 x-2 x$ blood volume exchange. We opted for a target Hct of $50 \%$ for the replacement fluid given the severity of the hemolytic anemia. Selected RBC units were $<15$ days of age, matched for Rh, Kell, Jk and other antigens as appropriate based on history and serology, and crossmatched against plasma or adsorbed plasma, if available. Because preparation of reconstituted WB is considered an open system with a 24 hour outdate, we prepared only one reconstituted WB unit at a time (i.e. after dispensing one unit, the next unit was prepared). WBEx was performed

This article is protected by copyright. All rights reserved. 
by physically removing WB with a syringe, followed by infusion of reconstituted WB. In adult patients, this involved removal of $200 \mathrm{~mL}$ ( $50 \mathrm{~mL}$ per draw with $60 \mathrm{~mL}$ syringes) over 10 minutes through a triple lumen central venous catheter, followed by infusion of WB over 1 to 1.5 hours. Overall, it required 20 hours to complete a manual WBEx exchange with 12 units WB as replacement. For pediatric patients, a similar process was followed using a central or femoral venous catheter $(5 \mathrm{~mL} / \mathrm{kg}$ per draw). We advise against the use of peripherally inserted central catheters (PICC) lines for manual WBEx based on our experience of losing PICC line access early in the process of a manual WBEx in both adult and pediatric patients.

We have performed manual WBEx in 3 patients with life-threatening AlHA with marked, sustained improvement in 2 patients. Our first patient was a 19-year old male with warm AlHA with hemolysis-induced hyperlipidemia, methemoglobinemia, hypertension, volume overload, hypoxia, in vivo RBC agglutination and worsening hemolysis despite high dose steroids, IVIG and splenectomy ${ }^{5}$. After a single WBEx, his hemoglobin was $7.7 \mathrm{~g} / \mathrm{dL}$ with resolution of autoagglutination, decrease in autoantibody (titers fell from 1000 to 256$)$, decreased methemoglobin (14\% to $1 \%$ ), and marked improvement in hemolysis and organ function (Figure 1). Our second case was a 4 yearold with severe WAIHA due to weak affinity IgG. A single WBEx increased his Hct from $5.4 \%$ to $33 \%$, decreased methemoglobin ( $15.4 \%$ to $2 \%$ ) and improved oxygenation (from 
$83 \% \mathrm{O}_{2}$ on $100 \% \mathrm{FiO} 2$ to $99 \% \mathrm{O}_{2}$ on room air). Similar results were reported in a $2-$

month and 10-year old who were also treated for AIHA using manual WBEx ${ }^{6,7}$. A single WBEx was also reported to rapidly improve hemolysis due to passenger lymphocyte syndrome in an $\mathrm{ABO}$-incompatible, allogeneic peripheral blood stem cell transplant ${ }^{11}$.

In contrast, WBEx may have limited efficacy in AIHA with a warm IgM component. We performed three manual WBEx in a post-transplant patient with a severe refractory mixed AlHA that included a warm IgM component. Although there was a transient improvement in Hct, severe hemolysis recurred within 48-72 hours after the procedure. Repeated WBEx also failed to suppress hemolysis in two other pediatric patients with warm IgM AIHA ${ }^{12,13}$. WBEx was also ineffective in cold AlHA due to anti-Pr 14 .

\section{B. Hyperleukocytosis and Other Indications}

Manual WBEx has been used to treat pediatric patients with hyperleukocytosis due to acute leukemia, pertussis, methemoglobinemia, poisoning, neonatal sepsis, thrombotic thrombocytopenia purpura (TTP), and Guillian-Barre syndrome ${ }^{4,15,16,17,18 \text {, }}$ $19,20,21,22,23,24,25$. Manual WBEx may be particularly advantageous in the setting of acute leukemia and sepsis because of the ability to also address anemia and clotting abnormalities. In neonatal sepsis, manual WBEx has been show to decrease overall

This article is protected by copyright. All rights reserved. 
mortality and improved renal output ${ }^{26}$. Manual WBEx for TTP and other disorders were performed due to the patient's young age or lack of apheresis services ${ }^{19,} 20,21,22$.

In small children (<10-15 kg body weight), manual WBEx may be a more suitable, safer and faster option than apheresis. Unlike apheresis, several venous access options are available for manual WBEx. In small children ( $\leq 10 \mathrm{~kg})$, leukoreduction can be performed faster by manual WBEx than leukapheresis with equivalent results ${ }^{4,16,17}$. A 10-year review at the University of Michigan showed that leukapheresis in this population took 8-24 hours due to access and procedure issues. In children $<10 \mathrm{~kg}$, a $2 \mathrm{x}$ blood volume leukapheresis averaged 3 hours due to the need for blood prime, slow inlet rate $(1-2 \mathrm{~mL} / \mathrm{kg} / \mathrm{min})$ and delays in establishing an interface. Since 2010, manual WBEx is performed in children $<10 \mathrm{~kg}$ for hyperleukocytosis.

In hyperleukocytosis and other conditions, manual WBEx has been performed with actual WB, or reconstituted WB with a Hct of $24 \%$ to $30 \%$. The exception is WBEx for pertussis, in which a Hct of $40 \%$ is recommended ${ }^{27}$. Alternatively, type-specific fresh WB from a donor can be used $4,19,20$.

\section{Semi-Automated WBEx Transfusion}

In the 1940's, WBEx transfusion was first used as a treatment for erythroblastosis fetalis. A continuous process using both arterial and venous umbilical 
vessels for flow was reported by Ata and Holman ${ }^{28}$. In this method, gravity was used to remove blood and replace at equal speeds. The use of dual infusion pumps for an isovolumetric exchange was reported by $\mathrm{Cropp}^{29}$. Subsequent modifications of this process introduced dual lumen catheters and different styles of infusion pumps $30,31,32$. In these semi-automated WBEx procedures, 1x WB volume exchange is usually performed in an isovolumetric fashion (Figure 2). The flow rate of the pumps removing and transfusing blood are equivalent and the replacement fluid is reconstituted WB from the blood bank. Because both circuits can be primed, there is minimal extracorporeal volume. The automation allows for greater flow speeds and more rapid completion of the procedure.

At Roswell Park, we used a semi-automated WBEx method to treat a 53 year-old adult with a malignancy-related AIHA refractory to steroids, IVIG, and the first dose of rituximab ${ }^{33}$. His initial hemoglobin of less than $4 \mathrm{~g} / \mathrm{dL}$ with accompanying chest pain was considered too low to allow for use of an automated apheresis device. Eight semiautomated WBEx procedures were performed over a 9-day period using approximately $1000 \mathrm{ml}$ of reconstituted WB per procedure. A central line was used for vascular access with the draw and return lines connected to separate infusion pumps. The replacement fluid was $\mathrm{RBC}$ reconstituted using $5 \%$ human serum albumin to a target $\mathrm{Hct}$ within $3 \%$ that of the WB being removed to reduce the risk of developing pulmonary edema during 
the procedure ${ }^{34}$. Limiting the Hct in the replacement fluid was based on a warning to individuals performing automated RBC exchange not to increase the Hct by more than $3 \%$ because of the significant risk of inducing pulmonary edema. Changes in the software now prevent this from occurring in the automated system. This patient continued to have active hemolysis but required less intensive RBC transfusion support.

\section{Fully Automated, Continuous-Flow WBEx Transfusion}

Three fully automated, continuous-flow methods for WBEx transfusion have been previously reported (Table 1). Berkessy reported a method using the Kiil dialyzer (both arterial tubing and venous tubing are pumped by the same roller-pump element to maintain constant blood volume) to treat hepatic coma and poisoning with nondialyzable substances ${ }^{35}$. Dorman successfully treated an adult patient with fulminant babesiosis with WBEx transfusion using the COBE Spectra RBC Exchange protocol and the following exchange program parameters: pre-exchange Hct 32\%, replacement fluid Hct 33\% (RBC reconstituted with plasma), target Hct 30\%, and FCR 30\% (fluid balance \% was not reported) ${ }^{36}$. Li et al reported clinical outcomes from a cohort of 30 adult patients with severe AIHA treated with WBEx transfusion using the COBE Spectra TPE protocol ${ }^{37}$. This procedure, however, required running the TPE procedure in manual mode so that the RBC line valve is closed to divert separated RBC and plasma together 
into the discard bag via the plasma line. Replacement fluids (donor RBCs and plasma) were not reconstituted beforehand, but are mixed in real-time within the replacement fluid tubing (i.e. replacement fluid spike \#1 to donor RBC, and spike \#2 to donor plasma).

In comparison, Bloodworks' validated WBEx protocol using the Spectra Optia is fully automated, and takes advantage of FDA 510(k) cleared Red Blood Cell Exchange (RBCX) protocol ${ }^{38}$. Based upon the observation at Bloodworks that a median plasma volume (PV) of 0.34 (interquartile range of 0.33 to $0.36 \mathrm{PV}$ ) is simultaneously exchanged in sickle cell patients on a chronic RBCX program using replacement fluid with median Hct of 56\%, and applying the principle of RBC conservation (i.e. (Total Blood Volume $(\mathrm{TBV}) \times$ target $\mathrm{Hct})+($ Remove Volume $\times$ Remove $\mathrm{Hct})=(\mathrm{TBV} \times \mathrm{pre}-\mathrm{Hct})+($ Replacement Volume $x$ Replacement Fluid Hct) ) in a closed patient-apheresis system, approximately a 1.0 PV can be exchanged while simultaneously achieving a fractional cell remaining (FCR) target of $35 \%$ by simply diluting the replacement fluid to the patient's preexchange $\mathrm{HCT}^{39}$.

This fully automated WBEx procedure was used to treat a 50 year-old adult with a new severe symptomatic WAIHA and an initial hemoglobin of $4.4 \mathrm{~g} / \mathrm{dL}$ refractory to steroid, IVIG, and rituximab despite a total of 40 units of Rh and Kell antigen-matched RBC transfusion support over 2 weeks ${ }^{40}$. A total of approximately 6.7 liters of

This article is protected by copyright. All rights reserved. 
replacement fluid (RBC reconstituted with $5 \%$ albumin to an expected Hct of $21 \%$ ) was used to achieve target Hct of $20 \%$ and FCR of $35 \%$ (Figure 3). The patient tolerated the WBEx procedure well, the initial run values were attained, and the antihuman globulin autoantibody titer fell from 8 to 2 . The patient eventually recovered after a prolonged hospital stay that included additional immunosuppressive therapies, including cyclophosphamide, and splenic-artery embolization.

\section{Conclusion}

As described, experiences from multiple institutions demonstrated that it is feasible to perform WBEx for several clinical indications. While the reported case number is small, some clinical benefit of WBEx has been shown for certain clinical indications. All of the reported methods and techniques have their own unique set up and challenges. More studies and technology advancement are needed in the future to firmly establish clinical indications as well as simplify WBEx technology.

This article is protected by copyright. All rights reserved. 


\section{References}

1. Schwartz J, Padmanabhan A, Aqui N, Balogun RA, Connelly-Smith L, Delaney M, Dunbar NM, Witt V, Wu Y, Shaz BH. Guidelines on the Use of Therapeutic Apheresis in Clinical Practice-Evidence-Based Approach from the Writing Committee of the American Society for Apheresis: The Seventh Special Issue. J Clin Apher. 2016 Jun;31(3):149-62

2. Dorman SE, Cannon ME, Telford SR 3rd, Frank KM, Churchill WH. Fulminant babesiosis treated with clindamycin, quinine, and whole-blood exchange transfusion. Transfusion. 2000 Mar;40(3):375-80.

3. Talacki CA, Ballas SK. Modified method of exchange transfusion in sickle cell disease. J Clin Apher. 1990;5(4):183-7.

4. Runco DV, Josephson CD, Raikar SS, Goldsmith KC, Lew G, Pauly M, Fasano RM. Hyperleukocytosis in infant acute leukemia: a role for manual exchange transfusion for leukoreduction. Transfusion. 2018 May;58(5):1149-1156

5. Cooling L, Boxer G, Simon R. Life-threatening autoimmune hemolytic anemia treated with manual whole blood exchange with rapid clinical improvement. J Blood Disorders Transf 2013;4:5.

6. Heidemann SM, Sarnaik SA, Sarnaik AP. Exchange transfusion for severe autoimmune hemolytic anemia. Am J Pediatr Hematol Oncol. 1987 Winter;9(4):3024.

7. Delores Y, Jacquot C, Criss V, Pary PP, Greenberg J, Luban NLC, Wong ECC. Management of severe autoimmune hemolytic anemia: A case report of an infant

This article is protected by copyright. All rights reserved. 
treated with manual whole blood exchange with rapid clinical improvement. Transfusion 2017;57(S3):124A.

8. Lawe JE. Successful exchange transfusion of an infant for AIHA developing late in mother's pregnancy. Transfusion. 1982 Jan-Feb;22(1):66-8.

9. Balaji SN, Trivedi V. Extracellular Methemoglobin Mediated Early ROS Spike Triggers Osmotic Fragility and RBC Destruction: An Insight into the Enhanced Hemolysis During Malaria. Indian J Clin Biochem. 2012 Apr;27(2):178-85

10. Balaji SN, Trivedi V. Extracellular methemoglobin primes red blood cell aggregation in malaria: an in vitro mechanistic study. FEBS Lett. 2013 Feb 14;587(4):350-7

11. Toren A, Dacosta Y, Manny N, Varadi G, Or R, Nagler A. Passenger B-lymphocyteinduced severe hemolytic disease after allogeneic peripheral blood stem cell transplantation. Blood 1996;87(2):843-844.

12. Friedmann AM, King KE, Shirey RS, Resar LM, Casella JF. Fatal autoimmune hemolytic anemia in a child due to warm-reactive immunoglobulin $\mathrm{M}$ antibody. J Pediatr Hem Oncol 1998;20(5):502-505

13. Nowak-Wegrzyn A, King KE, Shirey RS, Chen AR, McDonough C, Lederman HM. Fatal warm autoimmune hemolytic anemia resulting from IgM autoagglutinins in an infant with severe combined immunodeficiency. J Pediatr Hematol Oncol. 2001 May;23(4):250-2

14. Schonitzer D, Kilga-Nogler S, Trenkwalder B, Lisch $\mathrm{H}$, Brier $\mathrm{CH}$, et al. Autoimmunhamolyse durch anti-Pr. Infusionstherapie 1985;12:181-184.

15. Donoso AF, Cruces PI, Camacho JF, León JA, Kong JA. Exchange transfusion to reverse severe pertussis-induced cardiogenic shock. Pediatr Infect Dis J. 2006 Sep;25(9):846-8.

16. Rowlands HE, Goldman AP, Harrington K, Karimova A, Brierley J, Cross N, Skellett S, Peters MJ. Impact of rapid leukodepletion on the outcome of severe clinical pertussis in young infants. Pediatrics. 2010 Oct;126(4):e816-27

This article is protected by copyright. All rights reserved. 
17. Romano MJ, Weber MD, Weisse ME, Siu BL. Pertussis pneumonia, hypoxemia, hyperleukocytosis, and pulmonary hypertension: improvement in oxygenation after a double volume exchange transfusion. Pediatrics. 2004 Aug;114(2):e264-6.

18. Bhat $P$, Sisler I, Collier AB. Exchange transfusion as treatment for rasburicase induced methemoglobinemia in a glucose-6-phosphate dehydrogenase deficient patient. Pediatr Blood Cancer 2008;51(4):568.

19. Phillips BA, Riddell DG, Rogers PCJ, Carter JE. A case of probable thrombotic thrombocytopenic purpura responding to exchange transfusion. Am J Ped Hematol/Onc 1982:431-434.

20. Piastra M, Curro V, Chiaretti A, Viola L, Tortorolo L, Polidori G. Intracranial hemorrhage at the onset of thrombotic thrombocytopenic purpura in an infant: Therapeutic approach and intensive care management. Ped Emerg Care 2001;17(1):42-45.

21. Baranwal AK, Parmar VR. Exchange transfusion as an alternative therapy for recurrent severe Guillain-Barre syndrome. Indian J Ped 2007;74(7)689-691.

22. Singh S, Singhi S. Recovery from respiratory paralysis caused by Guillain-Barre syndrome in an infant after repeated exchange transfusions. Clin Pediatr 1989;28(10):480-481.

23. Tauscher JW, Polich JJ. Treatment of pine oil poisoning by exchange transfusion. J Pediatr 1959;55:511-515.

24. Zamani N, Hassanian-Moghaddam H, Ebrahimi S. Whole blood exchange as a promising treatment of aluminium phosphide poisoning. Arh Hig Rada Toksikol 2018;69(3):275-277.

25. Lederman S, Fysh WJ, Tredger M, Gamsu HR. Neonatal paracetamol poisoning: treatment by exchange transfusion. Arch Dis Child 1983;58(8):631-633

26. Pugni L, Ronchi A, Bizzarri B, Consonni D, Pietrasanta C, Ghirardi B, Fumagalli $M$, Ghirardello S, Mosca F. Exchange transfusion in the treatment of neonatal septic shock: A ten-year experience in a neonatal intensive care unit. Int J Mol Sci 2016;17(5):E695 
27. American Academy of Pediatrics. Pertussis in young infants. http://www.aapca.org/clinical/pertussis/pertussis_in_young_infants.html.

28. Ata $\mathrm{M}$, Holman $\mathrm{CA}$, Simultaneous umbilical arteriovenous exchange transfusion. $\mathrm{Br}$ Med J 1966;2(5516):743-745.

29. Cropp GJ. A continuous isovolumetric exchange transfusion technique. J Pediatr 1970;77: 881-883

30. Philpott MG, Banerjee A. Automated method for exchange transfusion. Arch Dis Child 1972;47(255): 815-818.

31. Goldman SL, Tu HC. Automated method for exchange transfusion: A new modification. J Pediatr 1983;102(1): 119-121

32. Funato M, Shimada S, Tamai H, Yamamoto M, Taki H. Automated apparatus for exchange transfusion. J Pediatr 1984;104(1):160

33. Becker JL, Scranton K. Semi-automating the whole blood exchange. J Clin Aph 2013;28(2):116

34. Vichinsky EP. Current issues with blood transfusions in sickle cell disease. Semin Hematol 2001;38(1 Suppl 1):14-22.

35. Berkessy S, Faludi G, Toth L, Hronszky L. Exchange blood-transfusion using artificialkidney equipment. Lancet 1972;2(7781):825

36. Dorman SE, Cannon ME, Telford SR 3rd, Frank KM, Churchill WH. Fulminant babesiosis treated with clindamycin, quinine, and whole-blood exchange transfusion. Transfusion 2000;40(3):375-380

37. Li BJ, Yuan X, Jian YJ, Ning-Li, Shu XW, Liu KL. Retrospective Analysis of 30 Severe Autoimmune Hemolytic Anemia Patients Treated By Whole Blood Exchange Transfusion. Transfusion 2015;55:2231-2237.

38. Wu Y, Collins L, Karr EG, Garcia A, Hagen-Coonradt A, Lin D, Sachais BS, Schwartz J, Witt V (2019). Apheresis Standard Operating Procedures Manual First Edition. Vancouver, BC: American Society For Apheresis.

This article is protected by copyright. All rights reserved. 
39. Bryan R, Gorospe JB, Fukuoka H, Pereyra L, Rowe JP, Popelka M, Collins H, Linn N, Yoon R, Villalon G, Pascua D, Gianan-Brown C, Prater S, Engle C, Nguyen A, Hopper L, Crandall D, Dutta K, Wong G, Dominguez G, Wu YY, Lin D. Method For Whole Blood Exchange Using Spectra Optia Automated Red Blood Cell Exchange Protocol. J Clin Apher 2018:33;155-156

40. Lin DM, Linn N, Bryan R, Goto $H$, Rowe JP, Popelka M, Collins $H$, Yoon R, GiananBrown C, Villalon G, Pascua D, Josue D, Wong G, Sardua R, Dominguez G, Denton K, Wu Y. Automated Whole Blood Exchange (WBEx) In The Treatment of Severe Autoimmune Hemolytic Anemia: A Case Report Of A Novel and Simple Protocol Using the Spectra Optia. J Clin Apher. 2019 May;33(2):XX

Table 1. Fully automated, continuous-flow methods for WBEx transfusion.

\begin{tabular}{|l|l|l|l|l|}
\hline $\begin{array}{l}\text { Author } \\
\text { (Year) }\end{array}$ & Instrument & Advantages & Disadvantages & Technical Aspects \\
\hline
\end{tabular}

This article is protected by copyright. All rights reserved. 


\begin{tabular}{|c|c|c|c|c|}
\hline $\begin{array}{l}\text { Berkessy } \\
\text { (1972) }\end{array}$ & Kiil dialyzer & $\begin{array}{l}\text { Fully automated, } \\
\text { continuous flow }\end{array}$ & Historical technology & $\begin{array}{l}\text { Both arterial tubing and } \\
\text { venous tubing are pumped } \\
\text { by the same roller-pump } \\
\text { element to maintain } \\
\text { constant blood volume }\end{array}$ \\
\hline $\begin{array}{l}\text { Dorman } \\
\text { (2000) }\end{array}$ & $\begin{array}{l}\text { COBE } \\
\text { Spectra, RBC } \\
\text { exchange } \\
\text { protocol }\end{array}$ & $\begin{array}{l}\text { Fully automated, } \\
\text { continuous flow }\end{array}$ & $\begin{array}{l}\text { Recently phased out } \\
\text { technology; } \\
\text { reconstituting RBC to } \\
\text { the intended Hct is } \\
\text { labor intensive }\end{array}$ & $\begin{array}{l}\text { Reconstitute RBC with } \\
\text { plasma to a target Hct as } \\
\text { close to the patient's pre- } \\
\text { exchange Hct, and program } \\
\text { FCR at } 30 \% \text {. }\end{array}$ \\
\hline Li (2015) & $\begin{array}{l}\text { COBE } \\
\text { Spectra, TPE } \\
\text { protocol }\end{array}$ & $\begin{array}{l}\text { Fully automated } \\
\text { (in manual } \\
\text { mode), } \\
\text { continuous flow }\end{array}$ & $\begin{array}{l}\text { Recently phased out } \\
\text { technology; } \\
\text { reconstituting RBC in } \\
\text { real-time may result in } \\
\text { variable replacement } \\
\text { fluid Hct }\end{array}$ & $\begin{array}{l}\text { RBC line valve is closed so } \\
\text { that WB is diverted (via the } \\
\text { plasma line) into the discard } \\
\text { bag. Replacement fluid spike } \\
\# 1 \text { to donor RBC, and spike } \\
\# 2 \text { to donor plasma. }\end{array}$ \\
\hline $\begin{array}{l}\text { Lin } \\
(2019)\end{array}$ & $\begin{array}{l}\text { Spectra } \\
\text { Optia, RBC } \\
\text { exchange } \\
\text { protocol }\end{array}$ & $\begin{array}{l}\text { Fully automated, } \\
\text { continuous flow }\end{array}$ & $\begin{array}{l}\text { Reconstituting RBC to } \\
\text { the intended Hct is } \\
\text { labor intensive }\end{array}$ & $\begin{array}{l}\text { Reconstitute RBC with } \\
\text { compatible fluid to Hct as } \\
\text { close to the patient's pre- } \\
\text { exchange Hct, and program } \\
\text { FCR at } 30 \text { to } 35 \% \text {. }\end{array}$ \\
\hline
\end{tabular}

This article is protected by copyright. All rights reserved. 
Fig 1. Clinical course of an adult male with life-threatening AIHA that was treated with manual WBEx. A) Improved hemoglobin (-), resolution of red cell autoagglutination $(-)$ and marked decrease in hemolysis and transfusion requirement following WBEx. B) Decrease in FiO2 requirement ( - - ) with extubation following manual WBEx and removal of methemoglobin.

Fig 2. Semi-automated WBEx procedures are isovolumetric, i.e. The flow rate of the pumps removing and transfusing blood are equivalent

Fig 3. Fully automated, continuous-flow method for WBEx using the Spectra Optia 


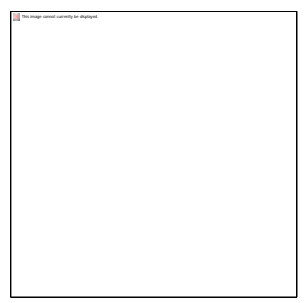

This article is protected by copyright. All rights reserved. 


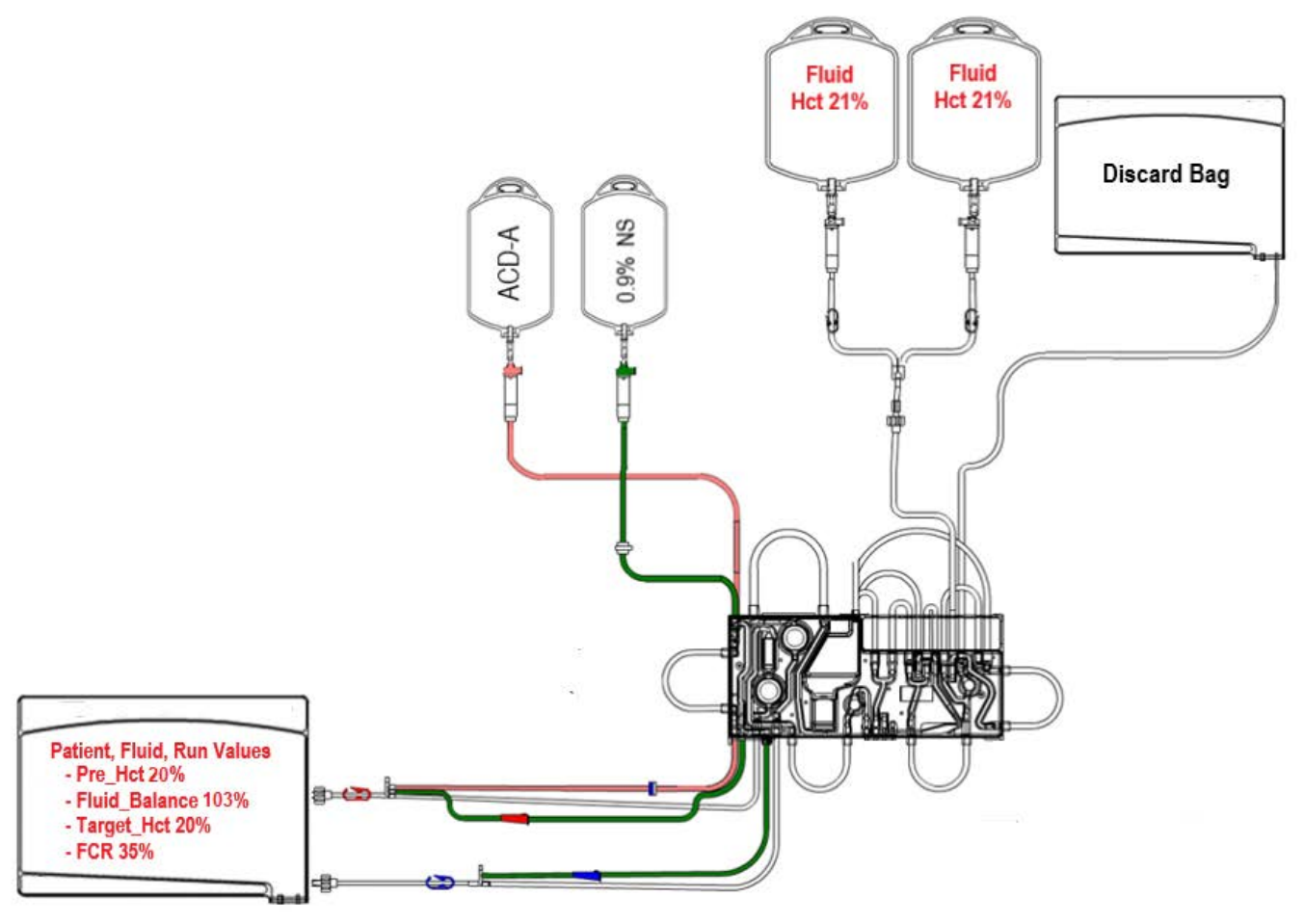

This article is protected by copyright. All rights reserved. 


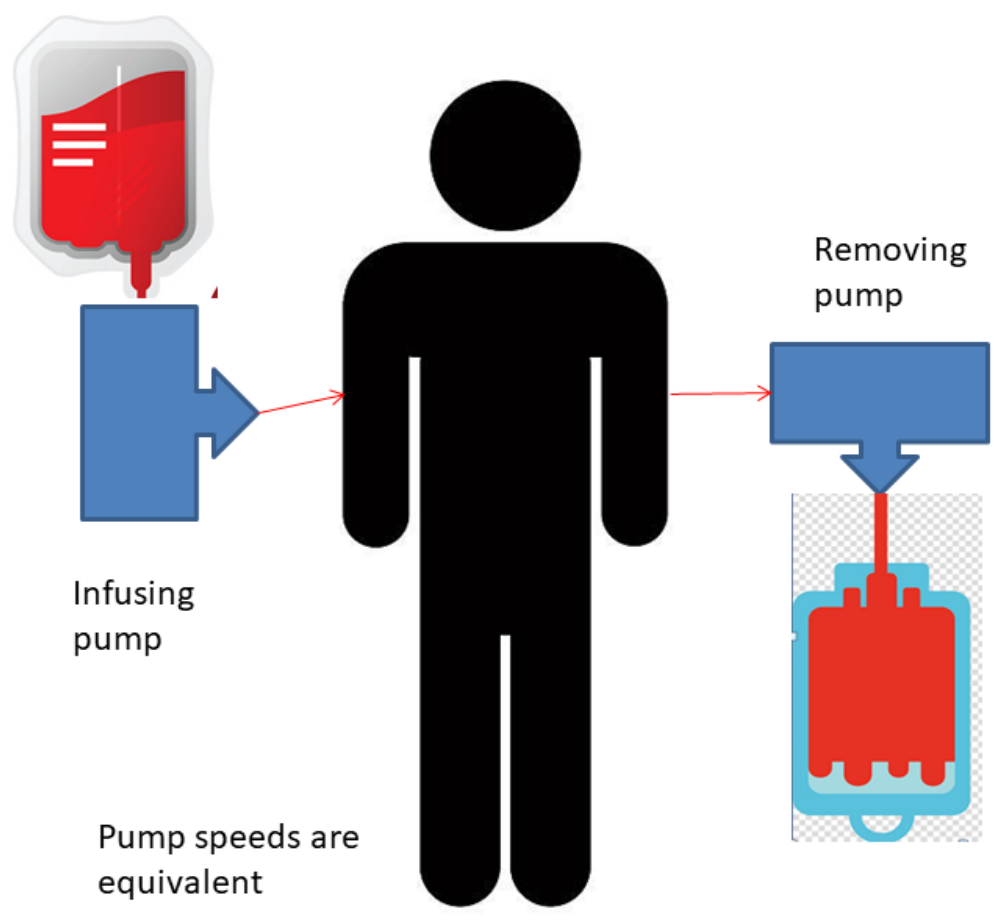

This article is protected by copyright. All rights reserved. 
12 units
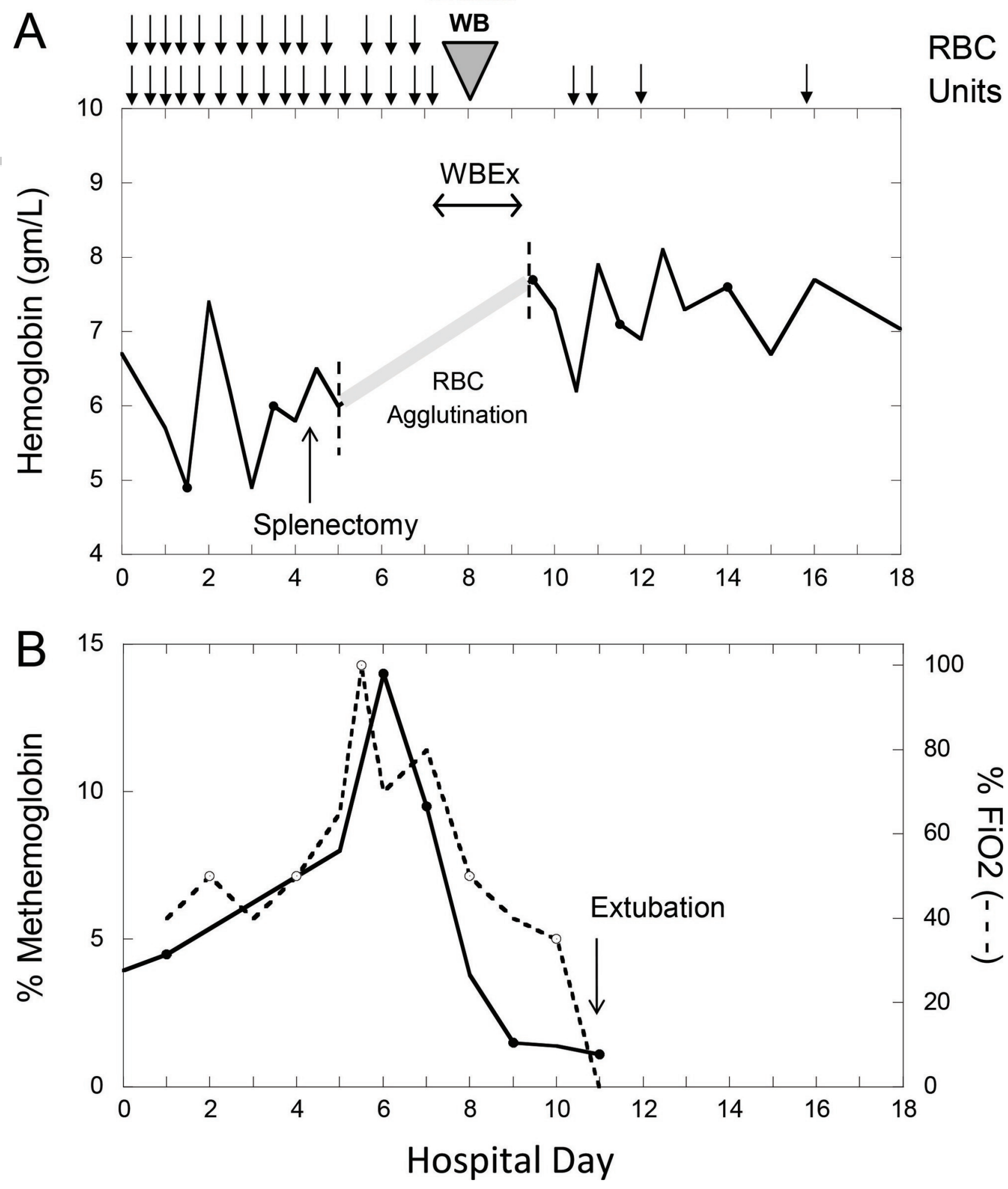

trf_15660_fig 1 submitted 06132019.eps 


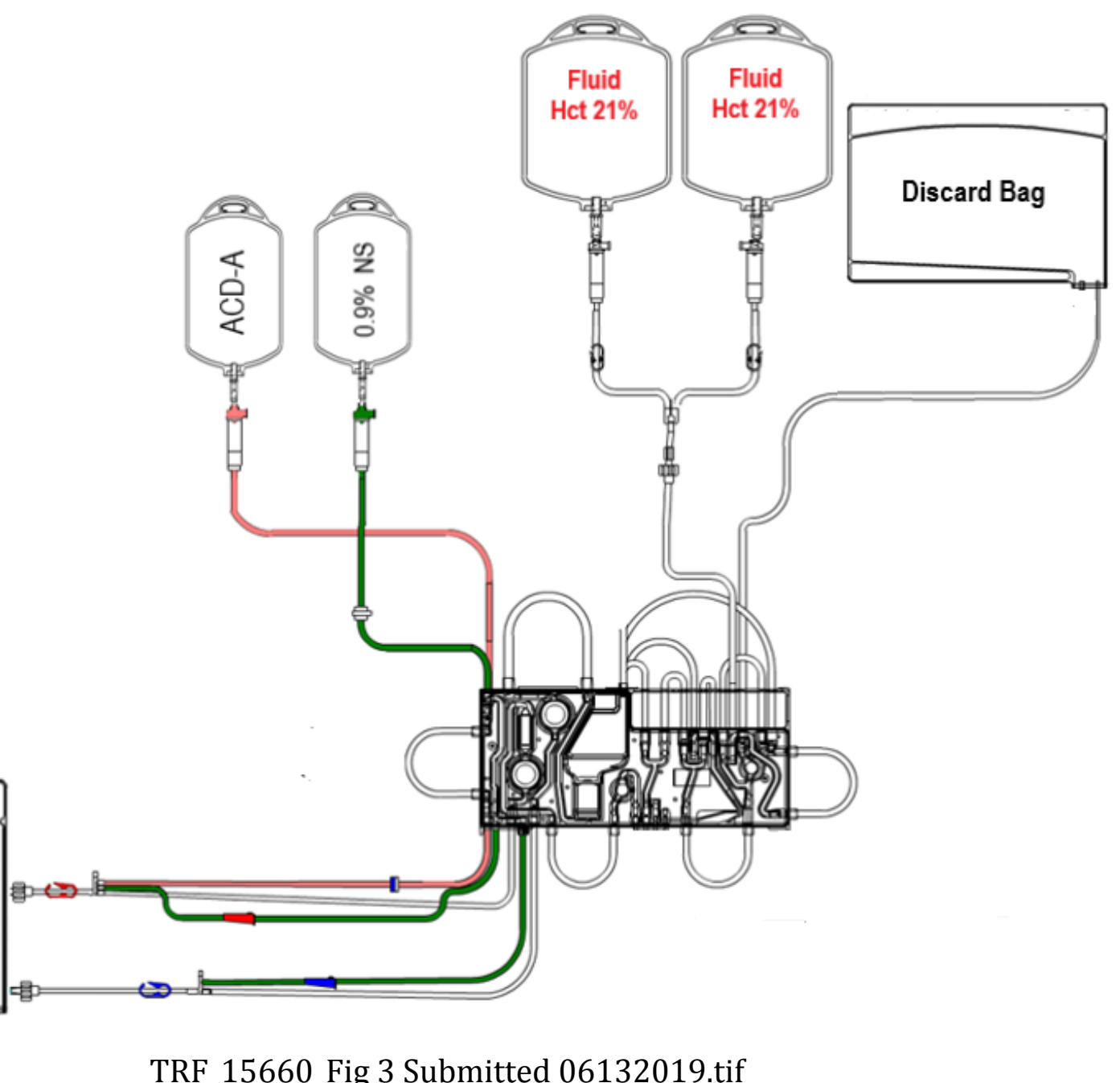

TRF_15660_Fig 3 Submitted 06132019.tif

This article is protected by copyright. All rights reserved. 


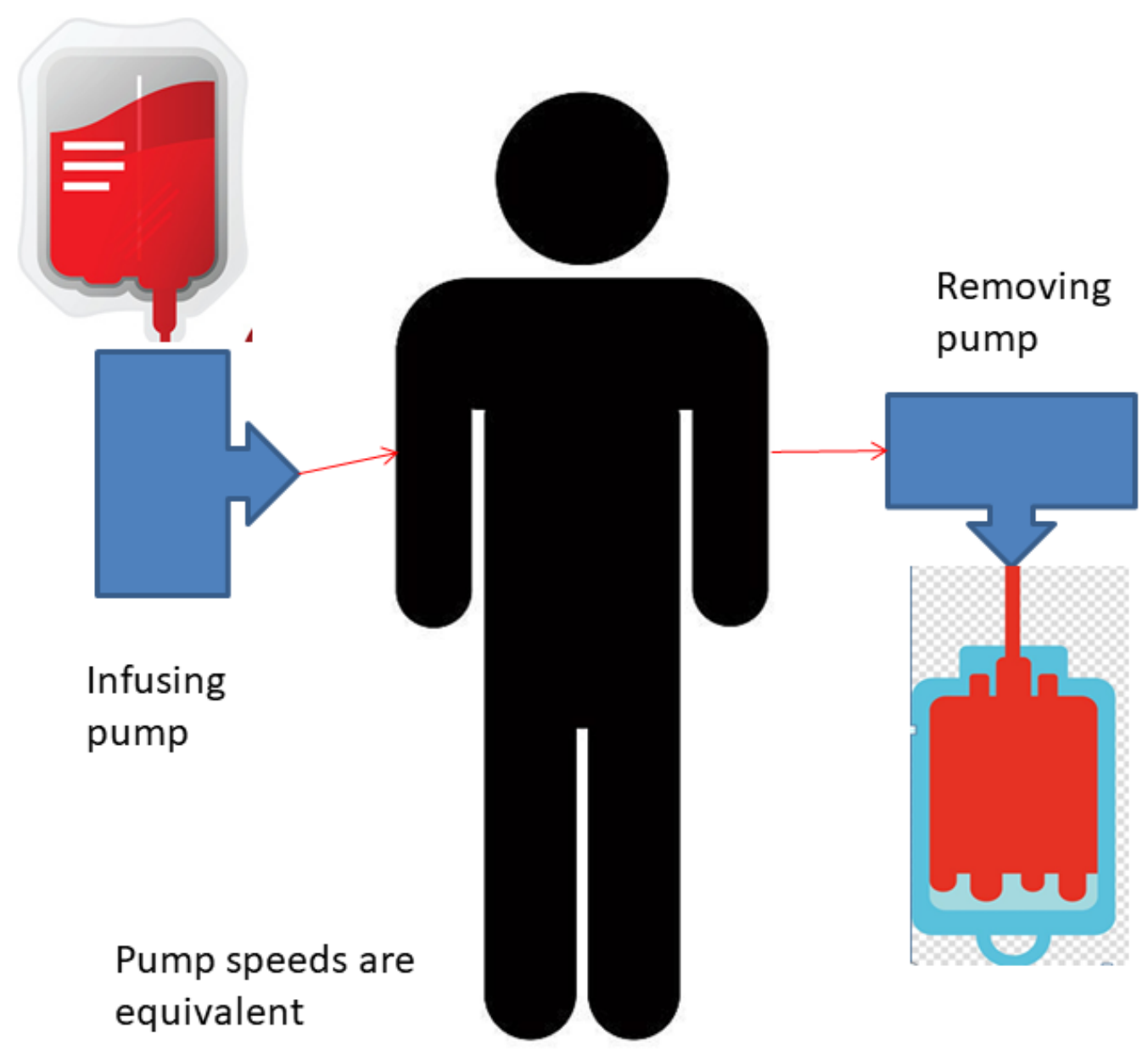

TRF_15660_Trans-2019-0303 Figure 2.tif

This article is protected by copyright. All rights reserved. 